\title{
Making Compelling Movie Posters Using Statistical Science And An Eye Mark Recorder
}

Kazunori Uchida, Aoyama Gakuin University, Japan Daisuke Kohara, Aoyama Gakuin University, Japan Maho Yamada, Aoyama Gakuin University, Japan

Kakuro Amasaka, Aoyama Gakuin University, Japan

\begin{abstract}
This study focuses on advertising posters for movies, investigating methods of designing compelling posters to encourage viewing. The results of questionnaire surveys were analyzed using statistical science to produce new movie poster designs. The effects of the new posters were then validated using an eye mark recorder. As a result, the authors have succeeded in creating a decision-making method to assist in designing compelling movie posters.
\end{abstract}

Keywords: Methodology for Decision Making of Design; Eye Mark Recorder; Movie Posters

\section{INTRODUCTION}

1 n today's society, with information constantly all around us, advertisements are a widely-used tool for linking companies and consumers. Total advertising expenditure during recent years has fallen below the level of previous years, affected significantly by the global recession and the economic slowdown due to the rapidly appreciating yen. Today, many companies are cutting their advertising expenditure, and it is now vital to be able to produce effective advertisements with even tighter budgets.

Thus, the authors have conducted a review of movie advertising. The AIDA theory organizes consumers' purchasing-related behavioral psychology into four stages: Attention, Interest, Desire, and Action. This study focuses on posters, which correspond to the first stage of advertising, in order to investigate compelling movie poster designs.

\section{RESEARCH BACKGROUND}

Last year, total advertising expenditure in Japan declined due to the impact of the global recession and the rapidly appreciating yen brought about by the financial crisis in America. Growth is also slow for the Japanese movie industry, with box-office revenue and the number of movie-goers remaining stagnant.

\section{Total Advertising Expenditure in Japan}

The authors looked into changes in Japan's Gross Domestic Product (GDP) and total advertising expenditure. Total advertising expenditure in Japan in 2008 (January to December) was 6.6926 trillion yen, which was $95.3 \%$ compared to the previous year and also the first decrease in five years. Due to the economic recovery in Japan and the increasing popularity of home electronic equipment and the Internet (broadband), total advertising expenditure increased in 2004 for the first time in four years. Expenditure continued to increase each year in 2005 (102.9\%), 2006 (101.7\%), and 2007 (101.1\%). However, in the latter half of 2008, expenditure fell below the level of 2007, affected significantly by factors such as the global recession triggered by the financial crisis in America, the economic slowdown due to the rapidly appreciating yen, and the sluggish economy at the end of 2007. 


\section{Movie-goer Ratio by Generation}

Analysis of the movie-going population reveals the following: The younger the generation, the higher the ratio of movie-goers. Conversely, the older the generation, the lower the ratio of movie-goers. However, for the last ten years, the ratio of movie-goers in their forties or older has been increasing, while the ratio for those between 10 and 29 years has been decreasing. The declining ratio of contact among younger generations is a serious problem for the movie industry, which needs to be addressed. Therefore, this study focuses on younger generations.

\section{QUESTIONNAIRE-BASED FIELD SURVEYS}

For this study, the authors conducted questionnaire surveys to determine how consumers perceive movie posters, and they analyzed the results. The questionnaire survey focused on university students and was conducted in two stages. The first questionnaire survey covered identifying consumer groups, the importance of movie posters, what people focus on when looking at the posters, and which factors influence people's interest and desire to watch movies. The second questionnaire looked at size and layout. The Analytic Hierarchy Process (AHP) was used for the layout. This questionnaire survey was conducted using the pair comparison method. The participants were shown posters of various sizes set by the researchers and were then asked to evaluate the posters on a seven-point scale.

\section{Movie Poster Elements}

Movie posters have several elements, such as the title, the main cast, the message, and the background. Survey participants were asked to evaluate the elements on a seven-point scale in order to determine which of the elements are considered most important by consumers. The consumer comments from the first questionnaire survey were analyzed through text mining, and the findings were represented as word networks.

Figure 1 shows the text mining results. The part indicated in the upper left shows that people find posters more appealing if they include close-ups of the cast's faces and a message. The part indicated in the upper right shows that people want to watch the movie if they understand what it is about. This means that they will be encouraged to watch the movie if the background shows a scene from the movie so they can get an idea of the storyline. and the cast.

These results show that the three important constituent elements of movie posters are the title, the message,

\section{Clarifying the Layout of Constituent Elements}

In this section, we will look at desired layouts for the important constituent elements obtained in the previous section. In determining effective layouts, the authors used AHP hierarchical analysis, which is a problemsolving and decision-making method.

The ultimate objective of this study is to achieve optimum layouts. The evaluation criteria are: a clearlyportrayed storyline, availability of information (cast, director, release date), and viewer-friendliness.

Six layouts were prepared using alternative proposals based on the positioning of the title, message, and cast at the top, in the center, or at the bottom. Figure 2 is a hierarchy diagram representing these layouts.

Next, questionnaire surveys were conducted using the pair comparison method. The surveys covered the three evaluation items for each of the six alternative proposals. AHP analysis was conducted using the results. A pair comparison matrix was used to determine the weight at each level and the overall weight, and the obtained results are shown in Tables 1 and 2. The tables demonstrate that proposal A has the largest weight value (0.38) and therefore is the optimum layout. 


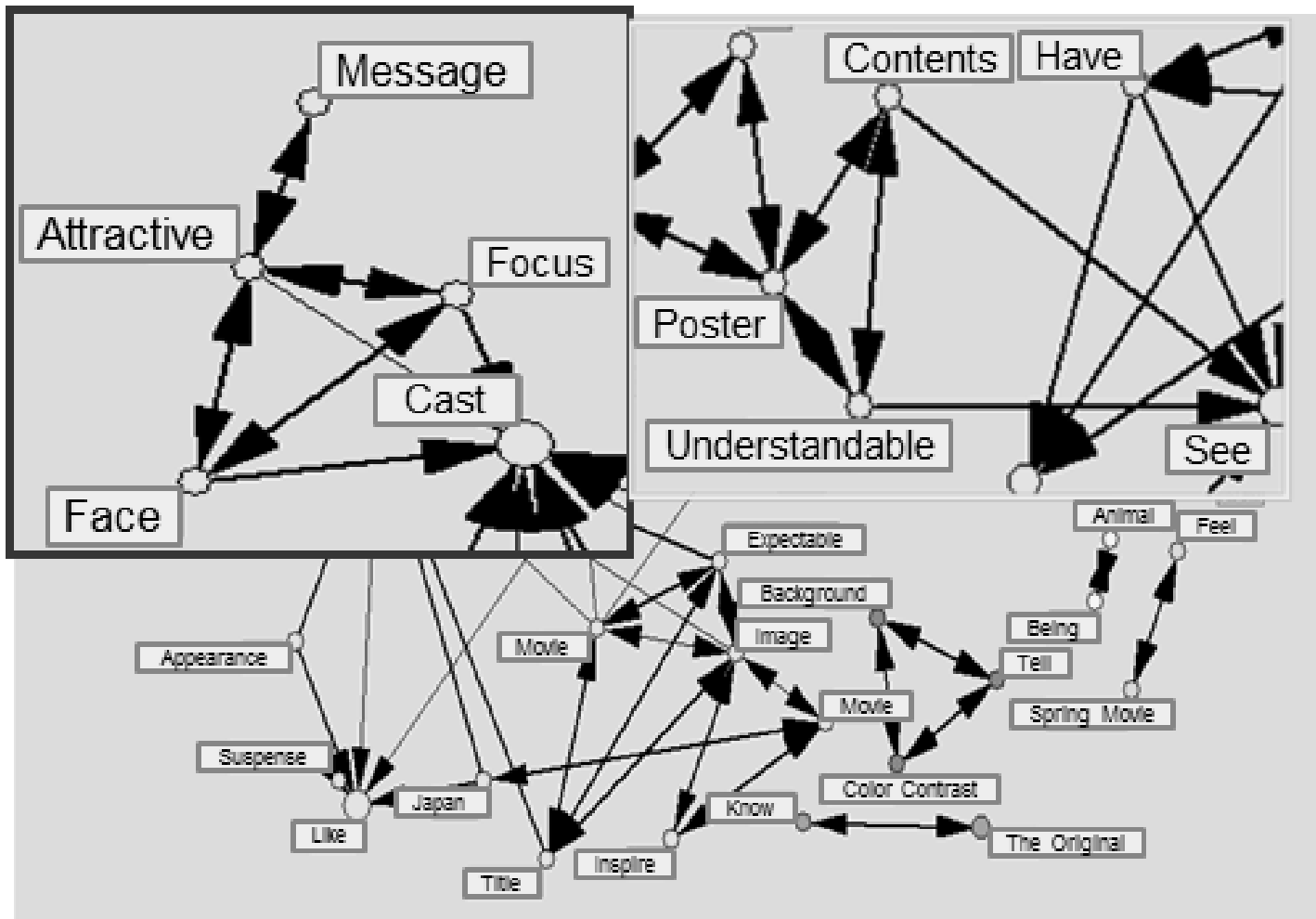

Figure 1: Word Networks

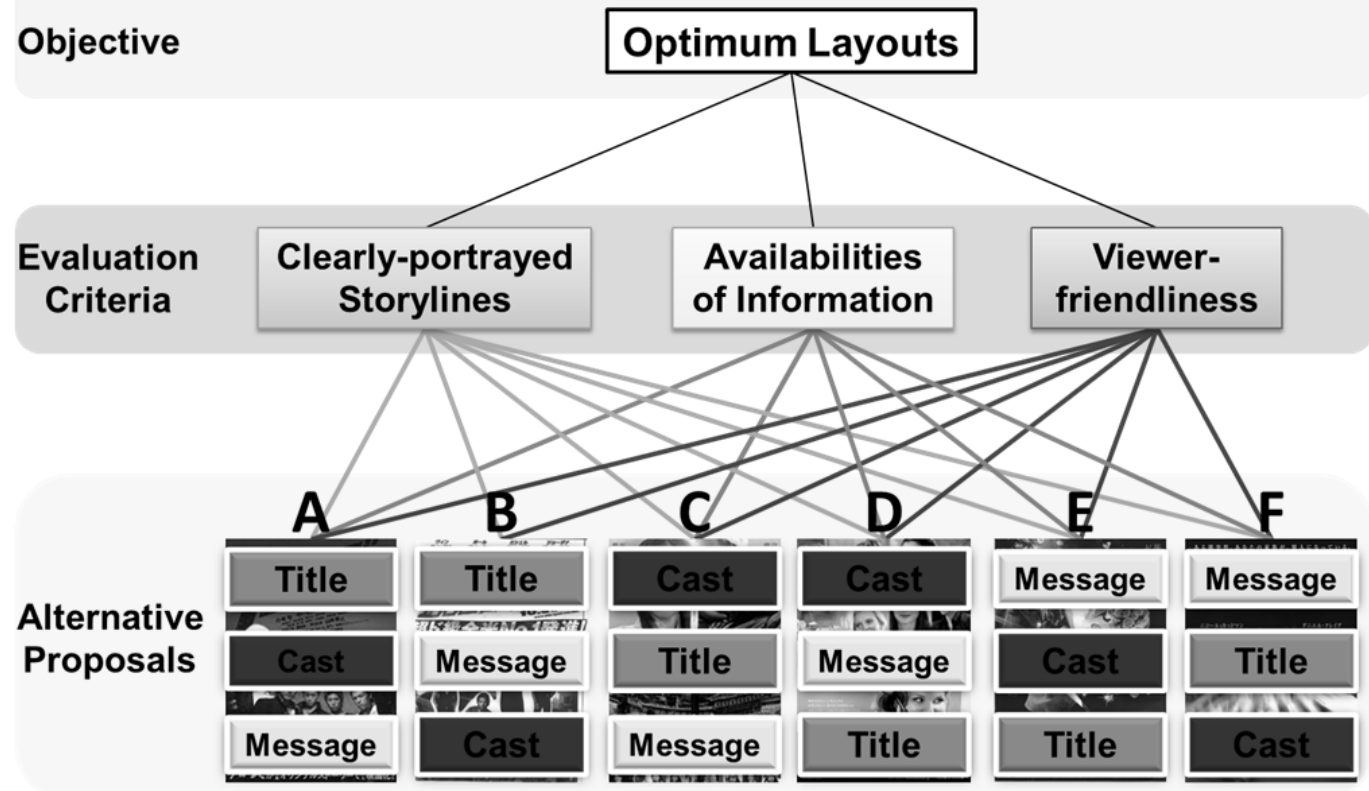

Figure 2: Hierarchy Diagram Showing the Layout of Constituent Elements 
Table 1: Weight for Each Criterion

\begin{tabular}{|l|c|}
\hline \multicolumn{1}{|c|}{ Evaluation Criteria } & Weight \\
\hline Clearly-portrayed Storylines & 0.39 \\
\hline Availabilities of Information & 0.05 \\
\hline Viewer-friendliness & 0.56 \\
\hline
\end{tabular}

Table 2: Weight and Overall Weight of Proposals for Each Criterion

\begin{tabular}{|c|c|c|c|c|}
\hline & $\begin{array}{c}\text { Clearly- } \\
\text { portrayed } \\
\text { Storylines }\end{array}$ & $\begin{array}{c}\text { Availabilities of } \\
\text { Information }\end{array}$ & $\begin{array}{c}\text { Viewer- } \\
\text { friendliness }\end{array}$ & $\begin{array}{c}\text { Overall } \\
\text { Weight }\end{array}$ \\
\hline A & 0.15 & 0.003 & 0.22 & 0.38 \\
\hline B & 0.04 & 0.02 & 0.02 & 0.08 \\
\hline C & 0.10 & 0.13 & 0.16 & 0.28 \\
\hline D & 0.03 & 0.01 & 0.06 & 0.09 \\
\hline E & 0.05 & 0.01 & 0.06 & 0.13 \\
\hline F & 0.01 & 0.002 & 0.03 & 0.04 \\
\hline
\end{tabular}

\section{Clarifying the Size of Constituent Elements}

In this section, we will look at desired sizes for the important constituent elements (title, message, cast) obtained in the Movie Poster Elements section. The objective was to select one element to be the main focal point from the design perspective, and then arrange the layout centering on this element to get the best effect when combined with the other elements.

Therefore, multiple linear regression analysis was used, enabling the focal element to be placed as an objective variable. A score representing the size of the focal element was set as an objective variable and scores representing the size of the other elements were set as explanatory variables.

Standard partial regression coefficient values were used to obtain the optimum combination of sizes for the three types. The standard partial regression coefficient values, which were obtained by standardizing the raw data, were used as an index when comparing the degree of influence of the objective variables among the explanatory variables.

The combinations used were chosen depending on the level of their descriptive contribution. Figure 3 shows the standard partial regression coefficients among constituent elements. This enabled three combinations of elements to be chosen: (1) Title-oriented: Title C + Cast B + Message C, (2) Cast-oriented: Title A + Cast E + Message B, and (3) Message-oriented: Title B + Cast B + Message B. 


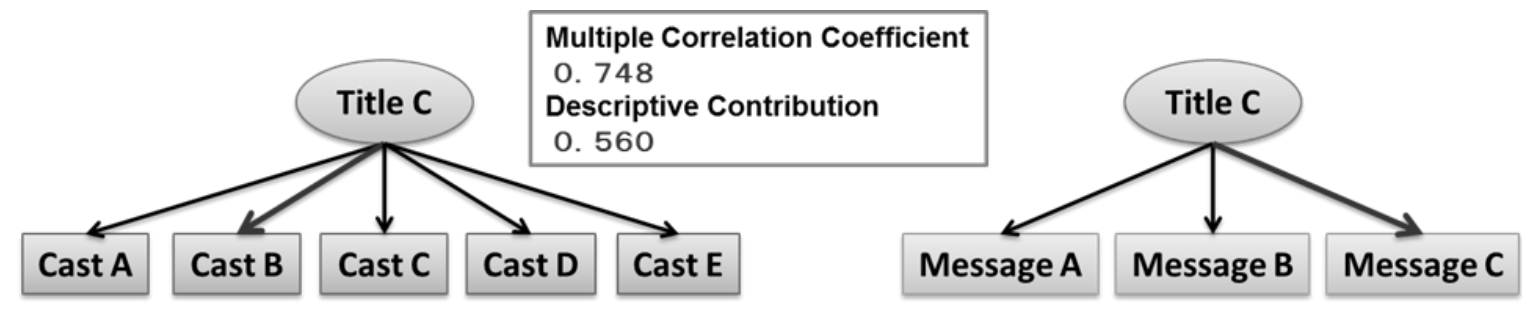

$-0.1580 .564-0.3030 .108$

0. 05

$-0.391-0.084$

0. 397

(a) Title-oriented

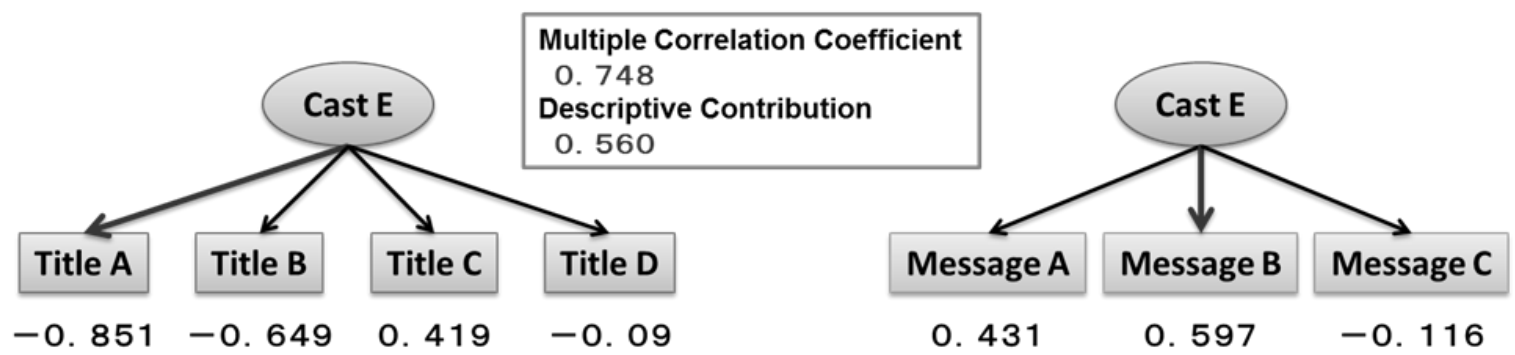

(b) Cast-oriented

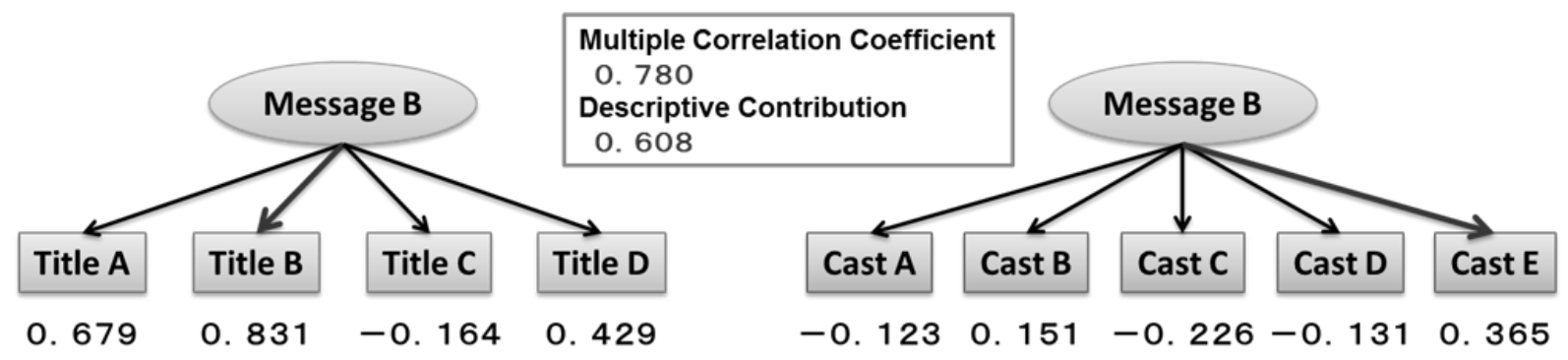

(c) Message-oriented

Figure 3: Standard Partial Regression Coefficients Among Constituent Elements 


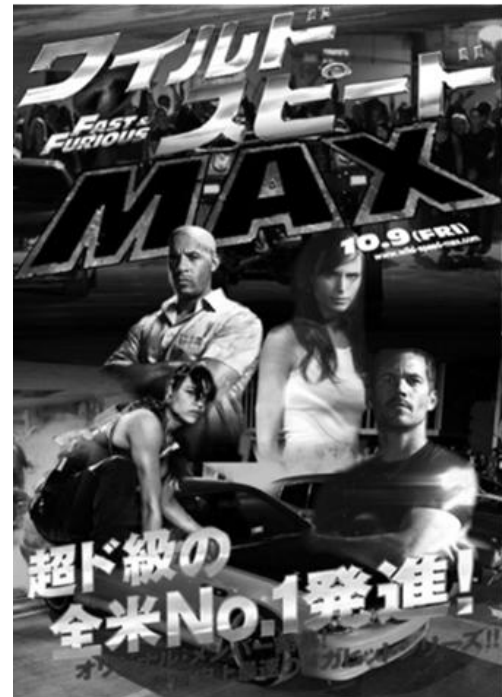

(a) Title-oriented

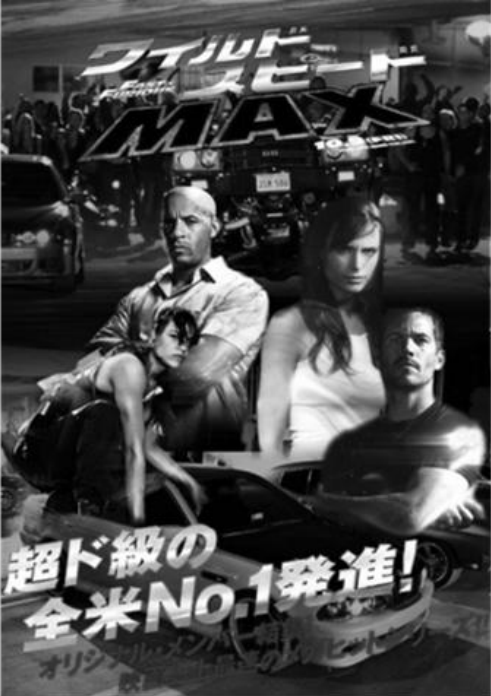

(b) Message-oriented

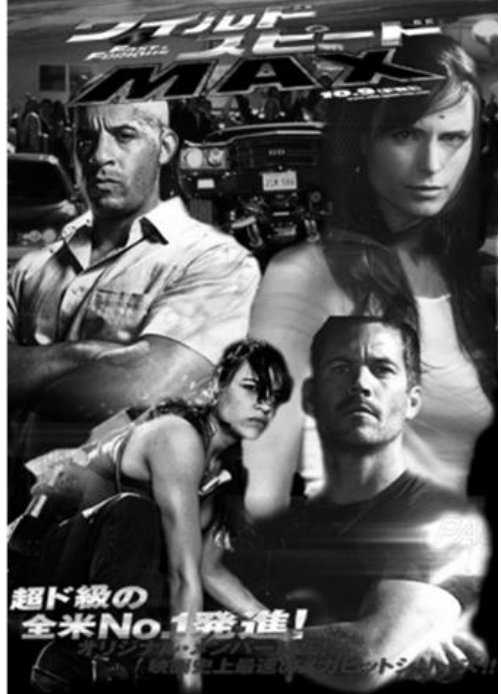

(c) Cast-oriented

Figure 4: New Posters

\section{Creating New Movie Posters}

Based on the analysis results so far, three posters were produced, each with a different focal element: Titleoriented, message-oriented, and cast-oriented. Figure 4 shows these new posters.

\section{VERIFICATION}

The new posters were compared with conventional posters to verify that they were more compelling. In order to determine the extent to which participants looked at the focal elements chosen by the researchers, an eye mark recorder was used to measure the line of sight. For verification, the three posters were put on a wall and the eye mark recorder was used to measure the proportion of time participants spent looking at each of the elements. Participants were allowed to view the posters freely with no time restrictions, just as they would if they went to a cinema.

Tables 3 to 5 show the results of the eye mark recorder tests for each of the focal elements. Table 3 shows that, as the producers of the posters intended, the participants spent the longest proportion of time $(61.2 \%)$ looking at the title. Similarly, both table 4 and 5 show that the participants spent most time looking at the focal elements chosen by the producers. All three of the posters succeeded in holding the participants' attention as the producers had intended.

Table 3: Title-oriented

\begin{tabular}{|lllll|} 
& Title & Cast & Message & Other \\
\hline Average & $16.1 \mathrm{sec}$. & $5.7 \mathrm{sec}$. & $3.0 \mathrm{sec}$. & $1.5 \mathrm{sec}$. \\
\hline Ratio & $61.2 \%$ & $21.5 \%$ & $11.5 \%$ & $5.8 \%$ \\
\hline
\end{tabular}


Table 4: Cast-oriented

\begin{tabular}{|lllll|}
\hline \multicolumn{1}{c}{ Title } & Cast & Message & Other \\
\hline Average & $3.2 \mathrm{sec}$. & $15.1 \mathrm{sec}$. & $2.5 \mathrm{sec}$. & $0.4 \mathrm{sec}$. \\
\hline Ratio & $15.2 \%$ & $70.9 \%$ & $11.8 \%$ & $2.0 \%$ \\
\hline
\end{tabular}

Table 5: Message-oriented

\begin{tabular}{|lllll|} 
& Title & Cast & Message & Other \\
\hline Average & $2.5 \mathrm{sec}$. & $6.2 \mathrm{sec}$. & $11.1 \mathrm{sec}$. & $0.2 \mathrm{sec}$. \\
\hline Ratio & $12.6 \%$ & $31.1 \%$ & $55.2 \%$ & $1.1 \%$ \\
\hline
\end{tabular}

\section{CONCLUSION}

Text mining was conducted based on the results of the questionnaire surveys, revealing the three important elements of movie posters (title, cast, and message). Effective layouts were then clarified using the AHP method. Then, multiple linear regression analysis was used to determine the optimum size of each element.

Based on the results of this analysis, three new types of poster were produced, focusing on different elements. An eye mark recorder was used to verify the results, and improvements were seen in the appeal of the posters. Thus, this study has been successful in creating more compelling movie posters to more effectively encourage consumers to watch movies.

\section{AUTHOR INFORMATION}

Kazunori Uchida is a graduate student of the College of Science and Engineering at Aoyama Gakuin University. Email: c5610164@aoyama.jp

Daisuke Kohara is received his Bachelor of Engineering degree from the College of Science and Engineering at Aoyama Gakuin University. E-mail: d_kohara_k@yahoo.co.jp

Maho Yamada is received his Bachelor of Engineering degree from the College of Science and Engineering at Aoyama Gakuin University. E-mail: maho_yamada@ hotmail.co.jp

Kakuro Amasaka is a Professor in the School of Science and Engineering at Aoyama Gakuin University, Japan. He received his Ph.D. degree in Precision Mechanical and System Engineering, Statistics and Quality Control at Hiroshima University in 1997. His current research and teaching interests are in the general area of production engineering. In particular, he is interested in New JIT. He is a chairman of JOMSA (2008-). E-mail: kakuro_amasaka@ise.aoyama.jp

\section{REFERENCES}

1. Amasaka, K. (2009), "The Effectiveness of Flyer Advertising Employing TMS: Key to Scientific Automobile Sales Innovation at Toyota“, The Academic Journal of China-USA Business Review, Vol.8, No.3, pp. 1-12.

2. Motion Picture Producers Association of Japan, Inc. Japanese Movie Industry Statistics. http://www.eiren.org/toukei/index.html

3. Kohara, D., Yamada, M., (2010) "Making Compelling Movie Posters Using Statistical Science and an Eye Mark Recorder", ICOSSSE'10 Proceedings of the 9th WSEAS international conference on System science and simulation in engineering, pp. 278-282 
4. Tanimura, M., (2005), Graduation thesis: "Consumer Behavior Model Using the AIDA Theory - Behavior Factor Analysis for TV Commercials and Newspaper Advertisements for Movies“, Aoyama Gakuin University

5. Zhang, W., (2003), "Twofunctions of Movie Posters-Popularing and Enjoyment", Dandong Vocational Technical College

6. Dentsu, "Estimated Range of Advertising Expenditure in Japan", http://www.dentsu.co.jp/marketing/adex/adex2008/_about.html

7. Kinoshita, E., (2003), "From Scientific Game Theory Based on Success and Failure to AHP", Tokuma Shoten

8. Miroslaw, J., (1992), "Evaluation of Advanced Construction Technology with AHP Method", Journal of Construction Engineering and Management, Vol.118, No.3, pp. 577-593

9. Barbara, G., (2006), "Managing risks in the supply chain using the AHP method", International Journal of Logistics Management, Vol.17, No.1, pp. 114-136

10. Amasaka, K., Nagazawa, S., (2000), "Basic and Advanced Sensory Evaluation for Sensitivity in Automotive Engineering“, Japanese Standards Association

11. John, P., (1991), "The use of eye mark recordings to support verbal retrospection in software testing ", Acta Psychologica, Vol.76, No.1, pp. 31-49 